\title{
Bidirectional Regulation of Aggression in Mice by Hippocampal Alpha-7 Nicotinic Acetylcholine Receptors
}

\author{
Alan S Lewis', Steven T Pittenger', Yann S Mineur', Dawson Stout', Philip H Smith ${ }^{2}$ and Marina R Picciotto*, \\ 'Department of Psychiatry, Yale University School of Medicine, New Haven, CT, USA; '²Department of Community Health and Social Medicine, \\ CUNY School of Medicine, New York, NY, USA
}

\begin{abstract}
Humans with I5q 3.3 microdeletion syndrome (15q/3.3DS) are typically hemizygous for CHRNA7, the gene coding for the $\alpha 7$ nicotinic acetylcholine receptor (nAChR), and manifest a variable neuropsychiatric phenotype that frequently includes persistent aggression. In mice, nAChR activation by nicotine is anti-aggressive, or 'serenic,' an effect which requires $\alpha 7$ nAChRs and is recapitulated by GTS-2I, an $\alpha 7$ $\mathrm{nAChR}$ partial agonist. Pharmacotherapies potentiating $\alpha 7 \mathrm{nAChR}$ signaling have also been shown to reduce aggression in human 15q 13.3DS. These findings identify the $\alpha 7 \mathrm{nAChR}$ as an important regulator of aggressive behavior, but the underlying neurobiological substrates remain to be determined. We therefore investigated the brain regions and potential neural circuits in which $\alpha 7 \mathrm{nAChRs}$ regulate aggressive behavior in male mice. As in 15q13.3DS, mice heterozygous for Chrna7 were significantly more aggressive compared to wildtype controls in the resident-intruder test. We subsequently examined the hippocampus, where $\alpha 7$ nAChRs are highly expressed, particularly in GABAergic interneurons. Resident-intruder interactions strongly activated granule cells in the dentate gyrus (DG). In contrast, GTS-2 I, which reduces aggression in mice, reduced DG granule cell activity during resident-intruder interactions. Short hairpin RNA knockdown of Chrna7 in the DG enhanced baseline aggression and eliminated the serenic effects of both nicotine and GTS-2I on attack latency. These data further implicate $\alpha 7 \mathrm{nAChRs}$ in regulation of aggression, and demonstrate that hippocampal $\alpha 7 \mathrm{nAChR}$ signaling is necessary and sufficient to limit aggression. These findings suggest that nAChR-mediated regulation of hippocampal excitatory-inhibitory balance could be a promising therapeutic intervention for aggression arising in certain forms of neuropsychiatric disease.

Neuropsychopharmacology (2018) 43, I267-1275; doi:I0.1038/npp.2017.276; published online 6 December 2017
\end{abstract}

\section{INTRODUCTION}

Improved understanding of neural circuits contributing to aggression is necessary to develop more effective therapeutic options for patients, including those with neuropsychiatric disorders. Syndromes associated with well-defined abnormalities at the genetic level can provide an important starting point to understand fundamental pathophysiological mechanisms. 15q13.3 microdeletion syndrome (15q13.3DS; OMIM \#612001) is a rare condition that results from the loss of part of the proximal portion of chromosome 15, an unstable genetic region prone to deletions and duplications (Sharp et al, 2008; Shinawi et al, 2009). The most common form of 15q13.3DS results from an $\sim 1.5$ megabase deletion that encompasses roughly six genes, including CHRNA7, the gene encoding the excitatory ligand-gated $\alpha 7$ nicotinic acetylcholine receptor (nAChR). This deletion is highly penetrant and results in a variable phenotype that frequently includes intellectual disability, seizures, neuropsychiatric disorders including autism spectrum disorder (ASD) or

\footnotetext{
*Correspondence: Dr MR Picciotto, Department of Psychiatry, Yale University School of Medicine, 34 Park Street, 3rd Floor Research, New Haven, CT 06508, USA, Tel: +203-737-204I, Fax: +203-737-2043, E-mail: marina.picciotto@yale.edu

Received 8 July 2017; revised 6 October 2017; accepted 30 October 2017; accepted article preview online 7 November 2017
}

schizophrenia, and behavioral problems including aggression (Sharp et al, 2008; Shinawi et al, 2009). Similar phenotypes are reported from smaller deletions encompassing only CHRNA7 and in at least some cases a portion of a neighboring gene, OTUD7A (Hoppman-Chaney et al, 2013; Masurel-Paulet et al, 2010; Mikhail et al, 2011; Shinawi et al, 2009). Furthermore, children and adolescents with aggressive behaviors severe enough to warrant antipsychotic treatment were recently reported to be far more likely to harbor deletions of CHRNA7 than the general population, with CHRNA7 deletion conferring an odds ratio of 184 for aggression (Gillentine et al, 2017). Mouse models of 15q13.3DS recapitulate multiple phenotypic aspects of the disorder, including abnormal electroencephalography and neuronal excitability, abnormal spatial memory and attention, and aggressive behavior following mild stressors (Fejgin et al, 2014; Nilsson et al, 2016). Taken together, evidence from human and animal studies suggests that abnormal genetic dosage of CHRNA7 and related neuronal signaling disturbance likely plays a causal role in some neurobehavioral aspects of the 15q13.3DS, including aggression regulation.

In a mouse model of aggression, we recently found the $\alpha 7$ $\mathrm{nAChR}$ was necessary for the anti-aggressive, or 'serenic' effects of systemic administration of the pan-nAChR agonist nicotine, and that GTS-21, an $\alpha 7 \mathrm{nAChR}$ partial agonist, 
recapitulated the serenic effects of nicotine (Lewis et al, 2015). In humans, galantamine, a positive allosteric modulator at the $\alpha 7 \mathrm{nAChR}$ and an acetylcholinesterase inhibitor, was reported to successfully reduce persistent, severe rage outbursts in a man with 15q13.3DS (Cubells et al, 2011), while transdermal nicotine successfully reduced persistent aggressive behavior in an adolescent with idiopathic ASD (Van Schalkwyk et al, 2015). Despite genetic and pharmacological evidence linking CHRNA7 to pathological aggressivity, the brain regions and neural circuitry important for aggression regulated by $\alpha 7 \mathrm{nAChRs}$ are not well understood. The $\alpha 7 \mathrm{nAChR}$ is highly expressed in the hippocampus of both mice (Baddick and Marks, 2011) and humans (Rubboli et al, 1994), where it is preferentially expressed on GABAergic interneurons and can inhibit activity of principal cells in multiple hippocampal regions (Frazier et al, 2003; Freedman et al, 1993; Ji and Dani, 2000). This organization suggests $\alpha 7$ nAChR signaling might regulate excitatoryinhibitory (E/I) balance in the hippocampus, which is commonly altered in neurodevelopmental conditions (Gao and Penzes, 2015) and directly linked to aggressive behavior (Kohl et al, 2013; van der Kooij et al, 2014).

We therefore investigated the brain regions critical to the regulation of aggressive behavior by $\alpha 7 \mathrm{nAChR}$ signaling in mice, focusing on the hippocampus. Our results have important implications for better understanding how neuromodulatory systems might influence brain regions within larger networks important for aggression. Furthermore, our results lend additional support to targeting E/I imbalance for treatment of pathological aggression, including pharmacological agents active at $\alpha 7 \mathrm{nAChRs,} \mathrm{which} \mathrm{are} \mathrm{well}$ tolerated in human studies (Freedman, 2014).

\section{MATERIALS AND METHODS}

\section{Animals}

Wild-type (WT) male C57BL/6 (B6) and Balb/c (B/c) mice were purchased from Jackson Laboratory (Bar Harbor, ME, USA) and habituated to the animal facility for at least 1 week. Male mice heterozygous for a null mutation of the $\alpha 7$ subunit (HET) (Orr-Urtreger et al, 1997) maintained on the B6 background for over 30 generations were bred with female B/ c mice to generate F1 WT and HET littermates. As B/c mice are significantly more aggressive than B6 mice, (Schneider et al, 1992), the enhanced baseline aggressivity of these F1 crosses leads to an increased number of bouts of aggressive behavior, and therefore greater power to detect small or medium effect sizes of Chrna7 heterozygosity using moderate sample sizes. Expression of $\alpha 7 \mathrm{nAChRs}$ was previously shown not to differ significantly between $\mathrm{B} 6$ and $\mathrm{B} / \mathrm{c}$ in multiple brain regions (Marks et al, 1983). Mice were housed under standard conditions with temperature maintained at $21 \pm 2{ }^{\circ} \mathrm{C}$ and a $12 \mathrm{~h}$ light-dark cycle with food and water available ad libitum. The Yale University Animal Care and Use Committee approved all procedures.

\section{Drugs}

All drugs were purchased from Sigma-Aldrich (St. Louis, $\mathrm{MO}, \mathrm{USA}$ ) and dissolved in phosphate-buffered saline (PBS, $0.1 \mathrm{M}, \mathrm{pH} 7.3)+0.2 \%$ DMSO for picrotoxin experiments or
PBS only for all other experiments. Nicotine hydrogen bitartrate was used for nicotine solutions, which were adjusted to $\mathrm{pH} 7.0 \pm 0.5$ with $1 \mathrm{M}$ sodium hydroxide and doses expressed as free base. All solutions were injected intraperitoneally (i.p.) $10-15 \mathrm{~min}$ prior to the start of resident-intruder tests at a volume of $10 \mathrm{ml} / \mathrm{kg}$ body mass. Drug administration was counterbalanced across animals for repeated-measures experiments.

\section{Resident-Intruder Test}

Resident-intruder tests were performed exactly as described previously (Lewis et al, 2015) and detailed in the Supplementary Materials and Methods.

\section{Locomotor Activity}

Mice were habituated to the test room for $1 \mathrm{~h}$, then placed in a clean, clear plexiglass rat cage for $30 \mathrm{~min}$. Activity was measured by horizontal and vertical infrared sensors (Fusion $\mathrm{HC}$ version 1.5, AccuScan Instruments, Inc., Columbus, $\mathrm{OH}, \mathrm{USA})$.

\section{Hippocampal Infusion of Adeno-Associated Viral Vectors Expressing Small Hairpin RNA (shRNA) Constructs}

Design, purification, and validation of viral vectors are described in Supplementary Materials and Methods. Viral vectors were infused bilaterally into the hippocampus using a stereotaxic frame mounted with $5 \mu$ l Hamilton syringes under $2 \%$ isoflurane anesthesia. An aliquot of $2 \mu \mathrm{l}$ of purified virus was infused into each side of the intermediate hippocampus (coordinates: anterior/posterior $=-3.08 \mathrm{~mm}$, lateral $= \pm 3.0 \mathrm{~mm}$, dorsal/ventral $=-3.2 \mathrm{~mm}$ ) over the course of $10 \mathrm{~min}$, and the syringe left in place for an additional $5 \mathrm{~min}$ to reduce backflow. Mice were subsequently single housed and allowed to recover for 3 weeks prior to behavioral testing. After testing, viral infusion sites were identified by GFP fluorescence in $40 \mu \mathrm{m}$ brain slices from paraformaldehyde (PFA)-perfused animals. Mice with evidence of GFP-positive cells in dentate gyrus (DG; either unilateral or bilateral) were included in behavioral analysis.

\section{Binding and Immunofluorescence (IF)}

$\alpha$-bungarotoxin binding was performed as previously described (Mineur et al, 2016). Cardiac perfusion, tissue sectioning, and IF staining for c-Fos were performed as previously described (Lewis et al, 2015). Staining for Arc (guinea pig, 1:1000, Synaptic Systems 156005, Goettingen, Germany), CaMKII (mouse, $1: 1000$, Abcam ab22609 [6G9], Cambridge, MA, USA), GABA (rabbit, 1:500, SigmaAldrich A2052), or GFP (rabbit, 1:1000, Life Technologies 11122, Carlsbad, CA, USA) was performed as detailed in the Supplementary Materials and Methods. For Arc-staining experiments, mice were perfused $90 \mathrm{~min}$ following the initiation of resident-intruder tests. 


\section{Microscopy and Image Analysis}

Images were acquired with an FV10i confocal microscope (Olympus, Tokyo, Japan) equipped with UPLSAP $\times 10$ (numerical aperture $(\mathrm{NA})=0.4)$ and $\times 60(\mathrm{NA}=1.2)$ objectives. Acquisition software was Olympus Fluoview Version 4.1a. Image analysis of c-Fos-stained sections was performed as previously described (Lewis et al, 2015). For Arc IF analysis, area of the DG upper blade was quantified by thresholding the DAPI image using Fiji (Schindelin et al, 2012), then Arc-positive cells were manually counted blind to condition and normalized to area. Only the DG upper blade was quantified as Arc expression in this region is substantially more dynamic than in the lower blade (Snyder et al, 2009). Data from left and right sides of two tissue sections were then averaged to obtain a single value per mouse from rostral or caudal DG. A single confocal z-slice was used for Arc quantification as well as for co-labeling experiments. Image adjustments were limited to changes in contrast, which were applied equally to the entire image and equally to experimental and control images for immunofluorescent target proteins.
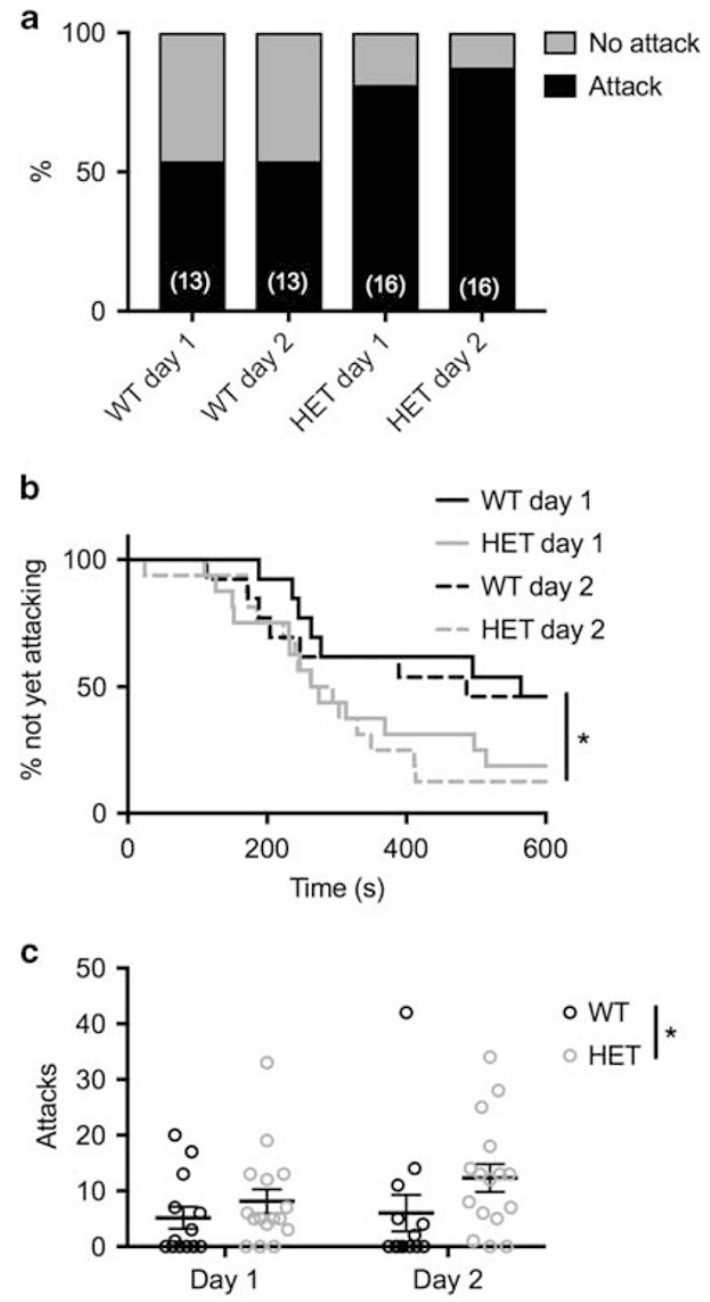

Figure I $\alpha 7$ nAChR HET mice on FI C57BL/6 $\times$ BALB/c background initiate attack in a greater percentage of bouts (a), initiate attack faster (b), and attack more (c) than WT littermates in resident-intruder tests. For all panels, $N=13, W T ; N=16, \mathrm{HET}$. Data in $\mathrm{c}$ are expressed as mean $\pm \mathrm{SEM}$. $* 0 \leqslant 0.05$ WT vs HET.

\section{Statistical Analysis}

Ordinary or repeated-measures (RM) analysis of variance (ANOVA) was used, as appropriate, to analyze the number of attacks and immediate early gene (IEG) staining. Between subject factors included 'genotype,' 'intruder,' and 'shRNA virus.' Within-subject factors included 'drug,' 'day,' and 'rostrocaudal location.' For violations of normality of error residuals in number of attack analysis, a $y=\log (y+1)$ transformation was used. Multiple comparisons to a control group were corrected using Dunnett's test. Analysis of attack latency was performed using parametric multi-level survival analysis exactly as previously described (Lewis et al, 2015). When low variability of data precluded appropriate use of survival analysis, RM-ANOVA on ranked dependent variable was performed (Zimmerman and Zumbo, 1993). Correlations were performed using Pearson correlation. All tests were two-tailed. Graphical results depict mean \pm standard error of the mean (SEM) unless otherwise specified. Values of $p \leqslant 0.05$ were considered significant. Survival analyses were conducted in Stata version 13.1, all other analyses were conducted using Graphpad Prism7 and SPSS (IBM, Version 24) for Mac.

\section{RESULTS}

$\alpha 7$ HET Mice Demonstrate Shorter Attack Latency and More Attacks than WT Littermates

Resident-intruder tests were performed to determine the effects of Chrna7 dose on aggressive behavior. HET mice rather than Chrna7 homozygous knockout mice were studied because most humans with 15q13.3DS are hemizygous at CHRNA7. While Chrna7 homozygous knockout mice are viable, humans with homozygous loss at 15q13.3 demonstrate profound neurological impairments, including encephalopathy and hypotonia (Spielmann et al, 2011), thus, it is unclear if aggressivity is a component of this condition. HET mice initiated attack in more bouts than did WT littermates on both test days (Figure 1a). HET mice also attacked significantly faster than WT littermates $(\mathrm{HR}=5.11 ; 95 \%$ confidence interval $(\mathrm{CI})=1.03,25.48 ; p=0.046)$ (Figure 1b). Analysis of variance revealed an effect of genotype on number of attacks $(\mathrm{F}(1,27)=5.93 ; p=0.022)$, no significant effect of day $(F(1,27)=0.46, p=0.50)$, and no significant attack $\times$ day interaction $(\mathrm{F}(1,27)=1.19, \quad p=0.29)$ (Figure 1c). No significant differences in locomotor properties were observed between WT and HET mice (Supplementary Figure S1). These data suggest that altering $\alpha 7 \mathrm{nAChR}$ gene dose is associated with an enhanced aggression phenotype, as observed in both mouse models and humans with 15q13.3DS.

Hippocampal Immediate Early Gene (IEG) Expression is Upregulated by Resident-Intruder Interactions and Reduced by $\alpha 7$ Agonist

In situ hybridization for Chrna7 from the Allen Brain Atlas (Lein et al, 2007) and $\alpha$-bungarotoxin binding to assembled $\alpha 7 \mathrm{nAChRs}$ verified a high level of hippocampal expression of this nAChR subtype in WT B6 mice (Figure 2a), consistent with previous studies (Baddick and Marks, 


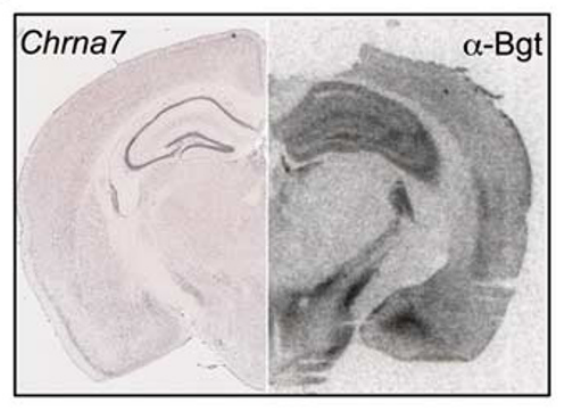

C

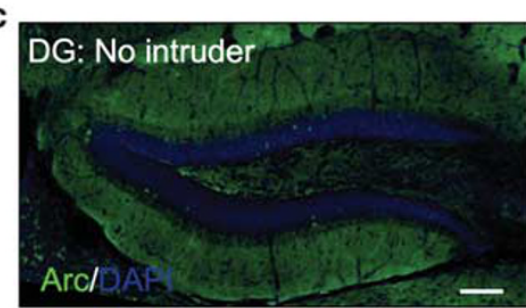

DG: + intruder

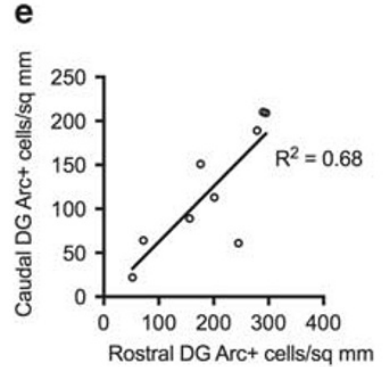

f b
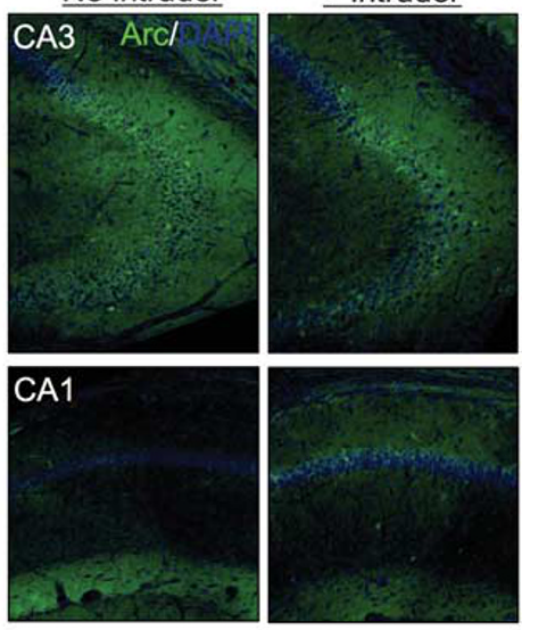

d

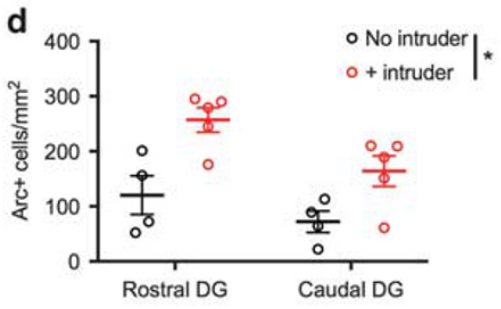

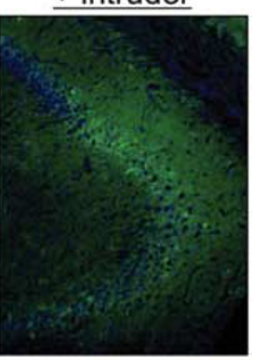
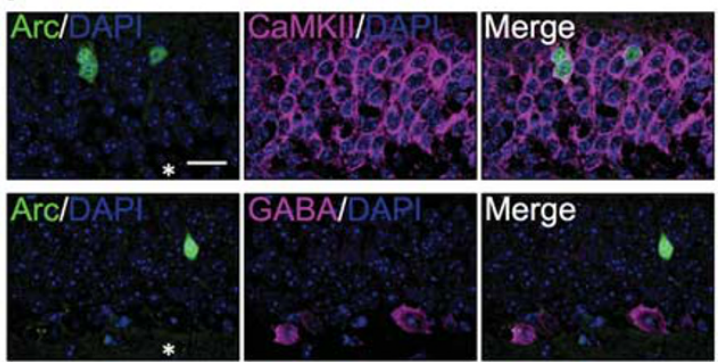

Figure 2 Resident-intruder interaction upregulates Arc immunoreactivity in rostral and caudal DG GCs of resident mice. In situ hybridization (ISH) for Chrna7 (a, left) and $\alpha$-bungarotoxin ( $\alpha$-Bgt) binding (a, right) demonstrate the enrichment of mRNA and assembled $\alpha 7$ nAChRs, respectively, in mouse hippocampus. Immunostaining for the immediate early gene Arc following resident-intruder tests in subregions of hippocampus reveals limited upregulation in CA3 and CAI (b), with strong upregulation in DG (c, d, N=4, no intruder, $N=5$, + intruder). Inset in lower panel of c is collapsed Z-stack of outlined region. Arc upregulation was similar in both rostral and caudal regions of the DG (e, N=9). Arc staining in the DG GC layer colocalizes with CaMKIl but not with GABA, suggesting the activated cells are excitatory DG GCs ( $f$ ). Data are expressed as mean \pm SEM. * $p \leqslant 0.05$. ISH in a is reproduced from the Allen Mouse Brain Atlas (Lein et al, 2007), Chrna7-745 I 1738, image 254 (http://mouse.brain-map.org/experiment/siv?id =745 I I 738\&imageld = 74362605\&initlmage = ish \&coordSystem $=$ pixel $\& x=5064.5 \& y=3744.5 \& z=1$ ). Asterisk in $\mathrm{f}$ denotes DG hilus. Scale bar in c (also applies to b): I00 microns. Scale bar in c inset and f: 20 microns.

2011). We thus focused on identifying hippocampal subregions strongly activated by aggressive interactions to determine whether these regions are regulated by $\alpha 7$ agonists with serenic effects. Staining for the IEG Arc in WT B6 mice did not appear qualitatively different in areas CA1 and CA3 following aggressive resident-intruder interactions in the home cage compared to home cage controls (Figure 2b). However, Arc was strongly upregulated in the granule cell (GC) layer of the DG in both rostral (dorsal) and caudal (ventral) regions under these conditions (Figure $2 c$ and $d$ and Supplementary Figure S2). Analysis of variance revealed main effects of intruder introduction $(F(1,7)=11.28$, $p=0.012)$ and rostrocaudal location $(\mathrm{F}(1,7)=18.24$, $p=0.0037)$. The intruder $\times$ location interaction was not significant $(\mathrm{F}(1,7)=1.83, p=0.22)$. A correlation between rostral and caudal DG Arc staining was observed $\left(R^{2}=0.68\right.$, $p=0.0064$ ), illustrating that DG GCs are activated across the rostrocaudal axis by aggressive encounters (Figure 2e).

Arc-positive cells consistently colocalized with CaMKII, a marker of DG GCs, but did not colocalize with GABApositive cells, which were frequently found in the subgranular region of the DG (Figure $2 \mathrm{f}$ ).

Dentate gyrus GC activation as a result of aggressive interactions suggests the DG may contribute to a network of 


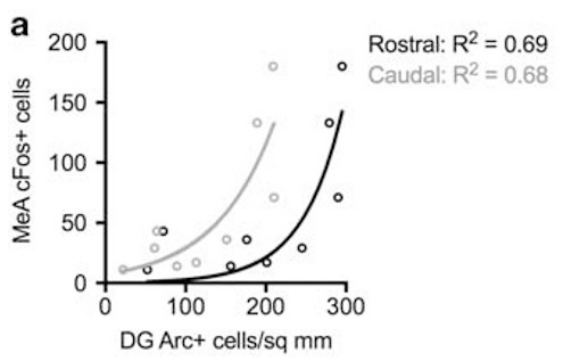

C

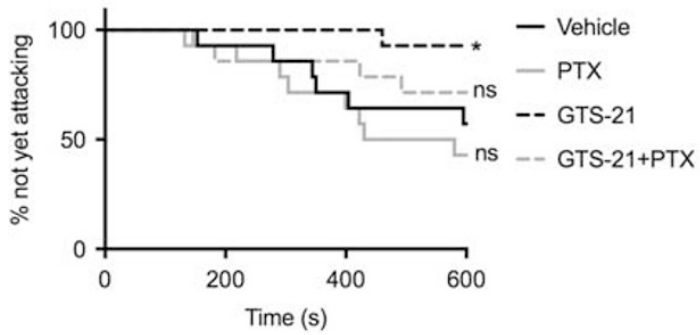

b
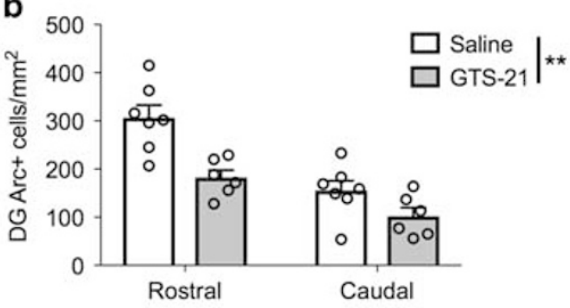

d

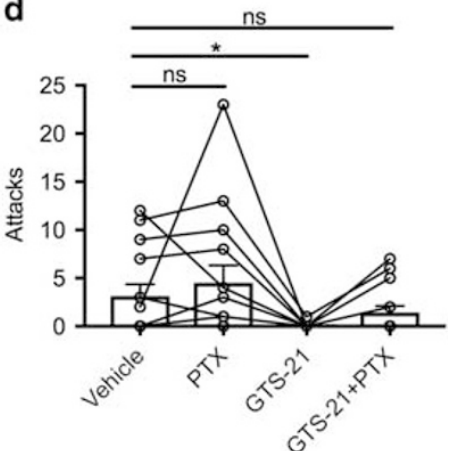

Figure 3 DG GC activity correlates with activity in other brain regions important for aggressive behavior, and the $\alpha 7$ nAChR partial agonist GTS-2I reduces DG GC activity. Arc immunostaining in rostral or caudal DG GCs and cFos immunostaining in medial amygdala (MeA) is fit by an exponential model (a, $N=9)$. GTS-2I (17 mg/kg) significantly reduced both rostral and caudal DG GC activity compared to saline, as measured by the number of Arc-positive neurons in mice undergoing resident-intruder tests that did not culminate in attack (b, $N=7$, saline; $N=6$, GTS-2I). The GABA-A antagonist picrotoxin (PTX, $0.1 \mathrm{mg} / \mathrm{kg}$ ) blunted the ability of GTS-2I (I7 mg/kg) to delay attack initiation (c) and to reduce total number of attacks (d) (c, d, N=I4 for all treatments, within-subject). Data are expressed as mean \pm SEM. $* 0 \leqslant 0.05$, ** $p \leqslant 0.0$ I vs vehicle treated group; ns, not significant.

brain regions regulating aggressive behavior. We therefore investigated the relationship between IEG staining in the rostral and caudal DG, and IEG staining in the posterior part of the medial amygdala, which contains populations of neurons critically important and highly specific for aggression in male mice (Unger et al, 2015). This within-brain correlation was fit by an exponential curve in both rostral and caudal DG, suggesting a threshold of DG activity may be permissive for further activation of brain regions involved in aggression initiation (Figure 3a). In this case, $\alpha 7$ agonists such as GTS-21, which delay attack onset (Lewis et al, 2015), might inhibit DG activation through enhancement of fast GABA-A-mediated inhibitory neurotransmission onto DG GCs (Frazier et al, 2003). To test this, we treated WT B6 mice undergoing resident-intruder tests with saline or GTS-21 $(17 \mathrm{mg} / \mathrm{kg})$, followed by Arc staining in rostral and caudal DG. We performed Arc staining in non-attacking animals, which allowed isolation of neural activity during a period when the resident is appraising the social environment and not confounded by motor or other processes related to attack initiation itself. Consistent with our hypothesis, ANOVA revealed a main effect of GTS-21 to reduce DG GC Arc staining $(\mathrm{F}(1,11)=14.82, p=0.0027)$, a main effect of rostrocaudal location $(\mathrm{F}(1,11)=37.36, p<0.0001)$, and no significant drug $\times$ location interaction $(\mathrm{F}(1,11)=3.52$, $p=0.088$ ) (Figure $3 \mathrm{~b}$ and Supplementary Figure S3). To further test the necessity of GABA-A signaling for the serenic effects of GTS-21, we systemically co-administered a nonepileptogenic low dose of the GABA-A antagonist picrotoxin (PTX, $0.1 \mathrm{mg} / \mathrm{kg}$ ) with GTS-21 (17 mg/kg) in WT B6 mice (Figure $3 c$ and d). GTS-21 significantly delayed time to attack and reduced number of attacks in B6 mice compared to vehicle. However, the addition of PTX to GTS-21 blunted its serenic effects, despite PTX itself not significantly altering aggressive behavior compared to vehicle (attack latency: $\mathrm{F}(3$, $39)=6.13, p=0.0016$; post hoc $v s$ vehicle (Dunnett corrected): PTX, $p=0.53$; GTS-21, $p=0.014$; GTS- $21+$ PTX, $p=0.57$; number of attacks: $\mathrm{F}(3,39)=6.24, p=0.0014$; post hoc $v s$ vehicle (Dunnett corrected): PTX, $p=0.64$; GTS-21, $p=0.010$; GTS-21 + PTX, $p=0.38$ ). Taken together, these results demonstrate DG GC activity is strongly upregulated by aggressive interactions, and suggest that $\alpha 7 \mathrm{nAChR}$ agonists such as GTS-21 and nicotine may lengthen the period before aggression initiation through enhancement of inhibitory GABAergic signaling in the $\alpha 7$ nAChR-rich DG.

\section{Knockdown of $\alpha 7$ nAChRs in the DG Speeds Attack Onset and Blunts Serenic Effects of Nicotine and GTS-21}

To determine more directly whether $\alpha 7 \mathrm{nAChRs}$ in the DG regulate aggressive behavior and are necessary for the serenic effects of $\alpha 7$ agonists, we infused adeno-associated virus 2 (AAV2) expressing shRNAs targeting $\alpha 7 \mathrm{nAChRs,} \mathrm{or} \mathrm{a}$ scrambled control, bilaterally into DG of WT male B/c mice (Figure $4 \mathrm{a}$ ). The $\mathrm{B} / \mathrm{c}$ strain was used in these experiments to enhance the number of bouts resulting in aggressive behavior (see 'Methods' section). Knockdown of $\alpha 7$ significantly shortened the latency to attack across 3 days of testing $(\mathrm{HR}=3.18 ; 95 \% \mathrm{CI}=1.01,9.97 ; p=0.048)$ (Figure $4 \mathrm{~b}-\mathrm{e})$. In contrast, there was no significant effect of virus on number of attacks $(F(1,13)=0.55, p=0.47)$ (Figure $4 f)$. We next tested whether $\alpha 7$ in the DG was necessary for the effects of 

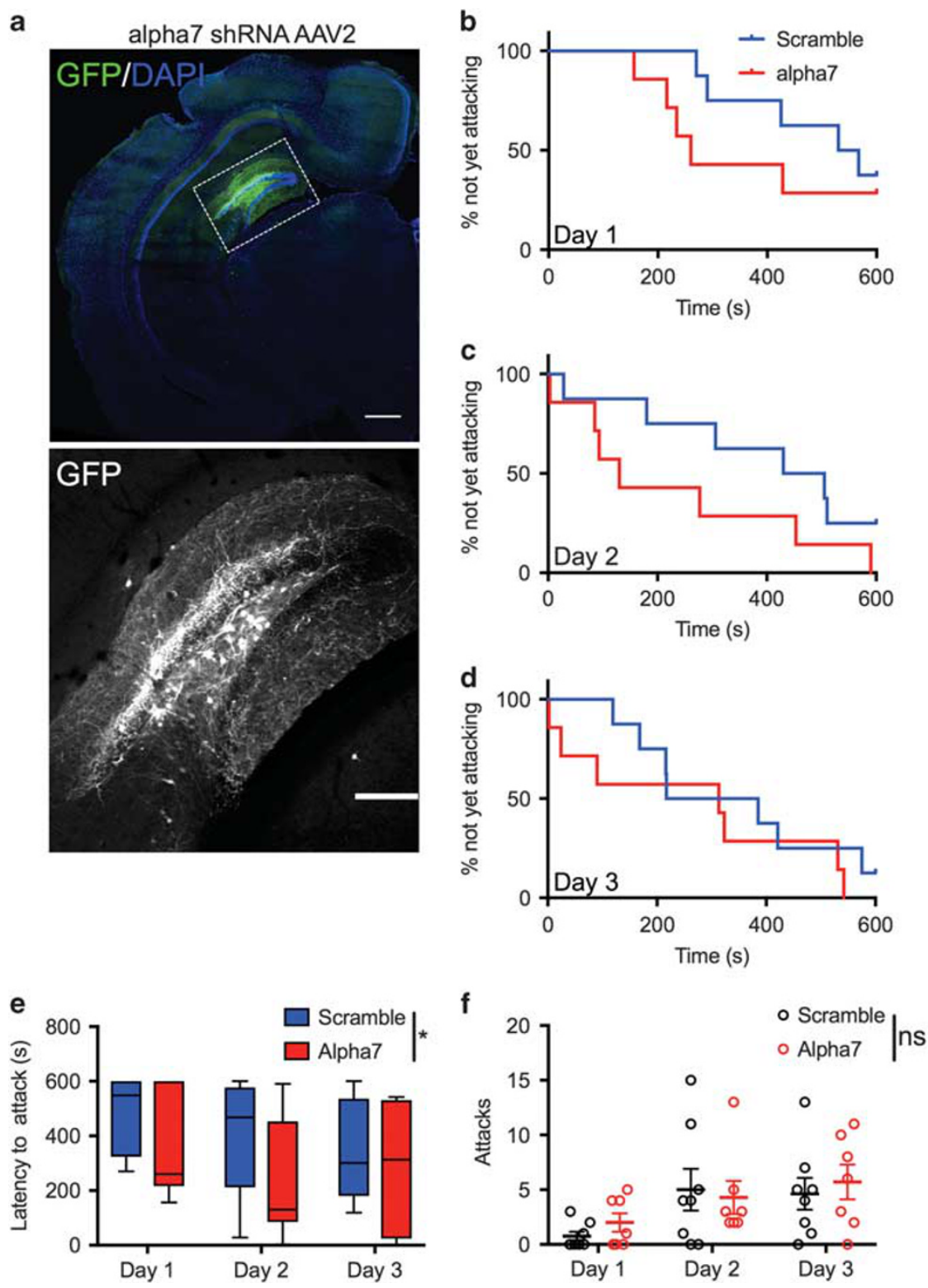

Figure 4 Delivery of shRNA targeting $\alpha 7$ nAChRs into the DG shortens attack latency, but does not influence number of attacks. AAV2-expressing shRNA was infused into the DG (a, lower panel is increased magnification of outlined region in upper panel). 'Time to attack' survival plots over 3 days of residentintruder testing in mice receiving scrambled shRNA $(N=8)$ or $\alpha 7$ shRNA $(N=7)(b-d)$, and Tukey box plot summarizing attack latency across days of testing (e), demonstrate shortened attack latency in mice receiving $\alpha 7$ shRNA. There was no significant effect of shRNA on number of attacks (f, $N=8$, scrambled shRNA; $N=7, \alpha 7$ shRNA). In e, center line depicts median latency, box depicts interquartile distance, whiskers extend to furthest data point. Data in $f$ are expressed as mean \pm SEM. $* 0 \leqslant 0.05$; ns, not significant. Scale bar in a: upper panel, 500 microns; lower panel, 200 microns.

$0.5 \mathrm{mg} / \mathrm{kg}$ nicotine and $20 \mathrm{mg} / \mathrm{kg}$ GTS-21 to lengthen time to first attack (Lewis et al, 2015). In the group of mice treated with vehicle or nicotine, we identified a significant drug $\times$ virus interaction $(\mathrm{HR}=8.92 ; 95 \% \mathrm{CI}=1.12, \quad 71.06$; $p=0.039)$. Nicotine treatment significantly delayed attack latency in mice receiving scrambled shRNA ( $\mathrm{HR}=0.10 ; 95 \%$ $\mathrm{CI}=0.02,0.47 ; p=0.004)$, but not in mice receiving $\alpha 7$ shRNA $(\mathrm{HR}=0.88,95 \% \mathrm{CI}=0.22,3.61 ; p=0.86$; Figure $5 \mathrm{a})$. In mice treated with vehicle or GTS-21 $(20 \mathrm{mg} / \mathrm{kg})$, the drug $\times$ virus interaction did not reach significance $(\mathrm{HR}=$ 2.58; 95\% CI $=0.43,15.38 ; p=0.297$ ). However, consistent with the results of nicotine treatment, planned comparisons revealed GTS-21 treatment significantly delayed attack latency in mice receiving scrambled shRNA $(H R=0.25$; $95 \% \mathrm{CI}=0.06,1.00 ; p=0.05)$ but not in mice receiving $\alpha 7$ shRNA $(\mathrm{HR}=0.65 ; 95 \% \mathrm{CI}=0.18,2.28 ; p=0.50$; Figure $5 \mathrm{~b})$. Taken together, these data suggest $\alpha 7$ nAChRs in the DG can affect attack latency bidirectionally.

\section{DISCUSSION}

Nicotine reduces aspects of aggressive behavior across diverse animal models of aggression (Picciotto et al, 2015), with recent studies suggesting these effects in mice require activation of $\alpha 7 \mathrm{nAChRs}$ (Lewis et al, 2015). Correspondingly, loss of CHRNA7 in humans confers substantial risk for 
a

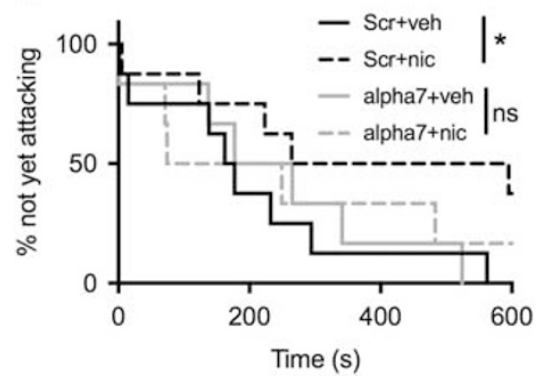

b

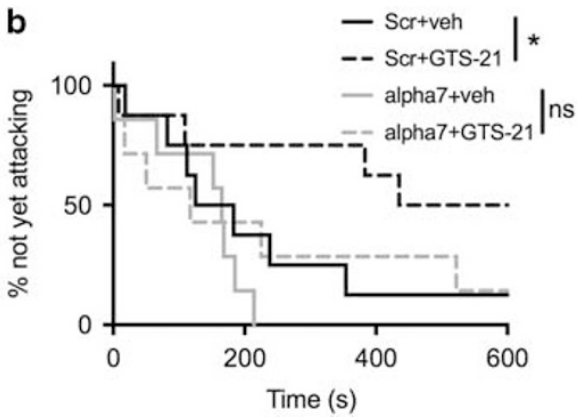

Figure 5 shRNA targeting $\alpha 7 \mathrm{nAChRs}$ in the DG blunts the effects of $0.5 \mathrm{mg} / \mathrm{kg}$ nicotine $(\mathrm{a}, \mathrm{N}=8$, scrambled shRNA; $N=6, \alpha 7$ shRNA) or $20 \mathrm{mg} / \mathrm{kg}$ GTS-2I ( $b, N=8$, scramble shRNA; $N=7, \alpha 7$ shRNA) to lengthen attack latency. ${ }^{*} p \leqslant 0.05$; ns, not significant.

aggressive behaviors (Gillentine et al, 2017), as well as other neuropsychiatric symptoms, with preliminary evidence that pharmacotherapy targeting the $\alpha 7 \mathrm{nAChR}$ may be effective for reducing aggression (Cubells et al, 2011). However, a definitive understanding of the relationship between $\alpha 7$ $\mathrm{nAChRs}$ and aggressive behavior remains elusive, especially given the genetic and behavioral heterogeneity of the 15q13.3DS in humans and behavioral studies in mice with Chrna7 deletion (Yin et al, 2017). Here we sought to further investigate the effects of $\alpha 7 \mathrm{nAChRs}$ on aggressive behavior in mice using a common behavioral test of aggression, and to identify important brain regions mediating the ability of $\alpha 7$ nAChRs to modulate aggression.

In our study, we found that $\alpha 7$ nAChR HET mice demonstrate faster attack latency and more attacks than WT littermates. Excitatory granule cells in the DG, a brain region with high expression of $\alpha 7 \mathrm{nAChRs}$ on inhibitory interneurons, are activated during aggressive interactions and the $\alpha 7$ partial agonist GTS-21, which delays attack latency, reduces GC activation. Finally, we demonstrated that knockdown of $\alpha 7 \mathrm{nAChRs}$ in the DG reduces time to first attack and blocks the ability of nicotine and GTS-21 treatment to delay attack. Together, these findings support a relationship between $\alpha 7 \mathrm{nAChR}$ signaling and aggressive behavior, and implicate $\alpha 7 \mathrm{nAChRs}$ expressed in the DG in the underlying mechanism.

A comprehensive behavioral battery recently reported no effect of $\alpha 7 \mathrm{nAChR}$ deletion in B6 mice, including in the tube test of social dominance in group-housed mice (Yin et al, 2017). Aggression in our study was measured by residentintruder tests following social isolation-induced aggression (Koolhaas et al, 2013). Previous work suggests these two tests measure different behavioral constructs (Lindzey et al, 1966). Furthermore, an effect of Chrna7 deficiency on aggression in B6 mice might be masked by this strain's limited propensity to initiate aggression (Schneider et al, 1992), which may have been improved by the use of $\mathrm{B} 6 \times \mathrm{B} / \mathrm{c} \mathrm{F} 1$ mice in the current study. Finally, aggression in the $\mathrm{Df}(\mathrm{h} 15 \mathrm{q} 13) /+$ mouse model of 15q13.3DS was observed in response to stress (Fejgin et al, 2014), which might have been engaged by the use of social isolation in our study.

Localization of $\alpha 7 \mathrm{nAChRs}$ in DG and hippocampus and their functional contributions to these circuits have previously been explored in rodents using $\alpha$-bungarotoxin binding, in situ hybridization, and electrophysiology. In humans, regional effects of $\alpha 7 \mathrm{nAChR}$ signaling have been assessed using pharmacology coupled with functional imaging. In the rodent DG, $\alpha 7 \mathrm{nAChRs}$ are preferentially localized to non-GCs, in particular GABAergic inhibitory neurons of a variety of subtypes, including those expressing neuropeptide-Y, somatostatin, and cholecystokinin (Frazier et al, 2003; Freedman et al, 1993; Son and Winzer-Serhan, 2008). Functionally, ACh acting on DG interneurons can produce inhibitory post-synaptic potentials on nearby GCs, as well as enhance inhibition on nearby GCs through a disynaptic pathway originating from entorhinal cortex glutamatergic inputs onto interneuron dendrites (Frazier et al, 2003). In agreement with physiological effects on inhibitory networks observed in rodents, GTS-21 in humans with schizophrenia normalizes excitation of the hippocampus during a smooth pursuit eye movement task (Tregellas et al, 2010). Because individuals with schizophrenia demonstrate abnormal activity of the hippocampus during this task compared to controls (Tregellas et al, 2004), the introduction of an $\alpha 7 \mathrm{nAChR}$ agonist may normalize an existing abnormality in E/I balance.

Consistent with these rodent and human studies, the current data also suggest an inhibitory effect of GTS-21 on DG GCs, presumably through its actions on $\alpha 7 \mathrm{nAChRs}$ on local inhibitory interneurons. Further, DG $\alpha 7 \mathrm{nAChRs}$ are necessary for GTS-21 to increase attack latency. Interestingly, HET mice appeared to be qualitatively more aggressive than mice with knockdown of Chrna7 in the DG, especially in total number of attacks (Figures 1 and 4). Although these mice differ in background strain as well as in surgical manipulation, this suggests that $\alpha 7 \mathrm{nAChRs}$ in brain regions outside the DG, including candidate regions rich in $\alpha 7$ nAChRs known to be important in aggression regulation such as the amygdala and prefrontal cortex (Unger et al, 2015), may contribute to the serenic effects of nicotinic drugs targeting $\alpha 7$ nAChRs. Overall, these data support a mechanism whereby the hippocampal E/I balance set point might regulate the likelihood of aggressive behavior. Such a mechanism is supported by previous studies of neuroligin-2, a postsynaptic cell adhesion protein necessary for proper hippocampal inhibitory neurotransmission linked to neuropsychiatric disorders such as ASD and schizophrenia. Viral overexpression of neuroligin-2 in the rat dorsal hippocampus increased expression of inhibitory synaptic markers and correspondingly reduced aggressive behavior (Kohl et al, 2013), while local hippocampal infusion of a peptide interfering with neuroligin-2 function increased aggressive 
behavior (van der Kooij et al, 2014). These studies extend work demonstrating the overall importance of the hippocampus in the regulation of aggression in animal models (Siegel and Flynn, 1968) and in humans with neuropsychiatric disorders (Sala et al, 2011; Vermeiren et al, 2014). Studies in humans with schizophrenia complicated by pathological impulsive aggression identify abnormal functional connectivity between ventral prefrontal cortex and amygdala (Hoptman et al, 2010) or other limbic structures (Hoptman et al, 2014). Future experiments might use rodent models of enhanced aggression related to changes in hippocampal E/I balance, such as the Chrna7 HET mice studied here, Df(h15q13)/+ mice (Fejgin et al, 2014), or rodents with neuroligin-2 manipulations, and perform molecular and physiological techniques to understand longrange regional interactions mediating enhanced aggressive behavior. In turn, results from such experiments might have potential translational importance for designing functional imaging experiments in human populations with neuropsychiatric disorders and co-morbid aggression.

Finally, the current results suggest that systematic investigation of pharmacological agents targeting $\alpha 7 \mathrm{nAChRs}$ is warranted to reduce pathological aggressive behavior in 15q13.3DS, and potentially other neuropsychiatric disorders with abnormal hippocampal E/I balance, such as idiopathic forms of ASD and schizophrenia (Gao and Penzes, 2015; Nelson and Valakh, 2015), as well as Alzheimer's disease (Rissman and Mobley, 2011). While a placebo-controlled trial demonstrated that nicotine patch can be beneficial for acute aggression in nicotine-dependent individuals with schizophrenia, evidence for efficacy of pharmacotherapies putatively targeting $\alpha 7$ nAChRs in 15q13.3DS (Cubells et al, 2011), idiopathic ASD (Van Schalkwyk et al, 2015), and dementia (Carmel and Sheitman, 2007; Rosin et al, 2001) remains limited to case reports. Importantly, the expression pattern of $\alpha 7$ nAChRs both at the regional level of the hippocampus and microcircuit level of inhibitory networks potentially permits a more specific targeting of neural substrates regulating aggressive behavior by $\alpha 7 \mathrm{nAChR}$ pharmacotherapy, as opposed to interventions targeting GABA receptors that are more widely expressed throughout the brain. The tolerability and safety of $\alpha 7$ agonists in humans with neuropsychiatric disorders, as well as the availability of biomarkers of response such as improvements in P50 gating deficits in schizophrenia (Olincy et al, 2006) or ASD (Olincy et al, 2016), would strongly support future evaluation of this therapeutic target for treating pathological aggression.

\section{FUNDING AND DISCLOSURE}

This work was supported by Autism Speaks Grant \#9699 (ASL) and by National Institutes of Health Grants R01DA014241, R01MH077681 (MRP), and R03MH105824 (YSM), The Avielle Foundation (DS), and R25MH071584, T32MH014276 (ASL). The authors declare no conflict of interest.

\section{ACKNOWLEDGMENTS}

We thank Samantha Sheppard and Nadia Jordan-Spasov for excellent technical assistance.

\section{REFERENCES}

Baddick CG, Marks MJ (2011). An autoradiographic survey of mouse brain nicotinic acetylcholine receptors defined by null mutants. Biochem Pharmacol 82: 828-841.

Carmel H, Sheitman BB (2007). Adjunctive transdermal nicotine reduced behavioral agitation in severe dementia. Am J Geriatr Psychiatry 15: 449.

Cubells JF, Deoreo EH, Harvey PD, Garlow SJ, Garber K, Adam MP et al (2011). Pharmaco-genetically guided treatment of recurrent rage outbursts in an adult male with $15 \mathrm{q} 13.3$ deletion syndrome. Am J Med Genet A 155A: 805-810.

Fejgin K, Nielsen J, Birknow MR, Bastlund JF, Nielsen V, Lauridsen JB et al (2014). A mouse model that recapitulates cardinal features of the 15q13.3 microdeletion syndrome including schizophreniaand epilepsy-related alterations. Biol Psychiatry 76: 128-137.

Frazier CJ, Strowbridge BW, Papke RL (2003). Nicotinic receptors on local circuit neurons in dentate gyrus: a potential role in regulation of granule cell excitability. $J$ Neurophysiol 89: 3018-3028.

Freedman R (2014). Alpha7-nicotinic acetylcholine receptor agonists for cognitive enhancement in schizophrenia. Annu Rev Med 65: 245-261.

Freedman R, Wetmore C, Stromberg I, Leonard S, Olson L (1993). Alpha-bungarotoxin binding to hippocampal interneurons: immunocytochemical characterization and effects on growth factor expression. J Neurosci 13: 1965-1975.

Gao R, Penzes P (2015). Common mechanisms of excitatory and inhibitory imbalance in schizophrenia and autism spectrum disorders. Curr Mol Med 15: 146-167.

Gillentine MA, White JJ, Grochowski CM, Lupski JR, Schaaf CP, Calarge CA (2017). CHRNA7 deletions are enriched in risperidone-treated children and adolescents. J Child Adolesc Psychopharmacol.

Hoppman-Chaney N, Wain K, Seger PR, Superneau DW, Hodge JC (2013). Identification of single gene deletions at 15q13.3: further evidence that CHRNA7 causes the 15q13.3 microdeletion syndrome phenotype. Clin Genet 83: 345-351.

Hoptman MJ, Antonius D, Mauro CJ, Parker EM, Javitt DC (2014). Cortical thinning, functional connectivity, and mood-related impulsivity in schizophrenia: relationship to aggressive attitudes and behavior. Am J Psychiatry 171: 939-948.

Hoptman MJ, D'Angelo D, Catalano D, Mauro CJ, Shehzad ZE, Kelly AM et al (2010). Amygdalofrontal functional disconnectivity and aggression in schizophrenia. Schizophr Bull 36: 1020-1028.

Ji D, Dani JA (2000). Inhibition and disinhibition of pyramidal neurons by activation of nicotinic receptors on hippocampal interneurons. J Neurophysiol 83: 2682-2690.

Kohl C, Riccio O, Grosse J, Zanoletti O, Fournier C, Schmidt MV et al (2013). Hippocampal neuroligin-2 overexpression leads to reduced aggression and inhibited novelty reactivity in rats. PLoS ONE 8: e56871.

Koolhaas JM, Coppens CM, de Boer SF, Buwalda B, Meerlo P, Timmermans PJ (2013). The resident-intruder paradigm: a standardized test for aggression, violence and social stress. $J$ Vis Exp 77: e4367.

Lein ES, Hawrylycz MJ, Ao N, Ayres M, Bensinger A, Bernard A et al (2007). Genome-wide atlas of gene expression in the adult mouse brain. Nature 445: 168-176.

Lewis AS, Mineur YS, Smith PH, Cahuzac EL, Picciotto MR (2015). Modulation of aggressive behavior in mice by nicotinic receptor subtypes. Biochem Pharmacol 97: 488-497.

Lindzey G, Manosevitz M, Winston H (1966). Social dominance in the mouse. Psychon Sci 5: 451-452.

Marks MJ, Burch JB, Collins AC (1983). Genetics of nicotine response in four inbred strains of mice. J Pharmacol Exp Ther 226: 291-302. 
Masurel-Paulet A, Andrieux J, Callier P, Cuisset JM, Le Caignec C, Holder $M$ et al (2010). Delineation of 15q13.3 microdeletions. Clin Genet 78: 149-161.

Mikhail FM, Lose EJ, Robin NH, Descartes MD, Rutledge KD, Rutledge SL et al (2011). Clinically relevant single gene or intragenic deletions encompassing critical neurodevelopmental genes in patients with developmental delay, mental retardation, and/or autism spectrum disorders. Am J Med Genet A 155A: 2386-2396.

Mineur YS, Fote GM, Blakeman S, Cahuzac EL, Newbold SA, Picciotto MR (2016). Multiple nicotinic acetylcholine receptor subtypes in the mouse amygdala regulate affective behaviors and response to social stress. Neuropsychopharmacology 41: $1579-1587$.

Nelson SB, Valakh V (2015). Excitatory/inhibitory balance and circuit homeostasis in autism spectrum disorders. Neuron 87: 684-698.

Nilsson SR, Celada P, Fejgin K, Thelin J, Nielsen J, Santana N et al (2016). A mouse model of the 15q13.3 microdeletion syndrome shows prefrontal neurophysiological dysfunctions and attentional impairment. Psychopharmacology 233: 2151-2163.

Olincy A, Blakeley-Smith A, Johnson L, Kem WR, Freedman R (2016). Brief report: initial trial of alpha7-nicotinic receptor stimulation in two adult patients with autism spectrum disorder. J Autism Dev Disord 46: 3812-3817.

Olincy A, Harris JG, Johnson LL, Pender V, Kongs S, Allensworth D et al (2006). Proof-of-concept trial of an alpha7 nicotinic agonist in schizophrenia. Arch Gen Psychiatry 63: 630-638.

Orr-Urtreger A, Goldner FM, Saeki M, Lorenzo I, Goldberg L, De Biasi $M$ et al (1997). Mice deficient in the alpha7 neuronal nicotinic acetylcholine receptor lack alpha-bungarotoxin binding sites and hippocampal fast nicotinic currents. J Neurosci 17: 9165-9171.

Picciotto MR, Lewis AS, van Schalkwyk GI, Mineur YS (2015). Mood and anxiety regulation by nicotinic acetylcholine receptors: a potential pathway to modulate aggression and related behavioral states. Neuropharmacology 96(Pt B): 235-243.

Rissman RA, Mobley WC (2011). Implications for treatment: GABAA receptors in aging, down syndrome and Alzheimer's disease. J Neurochem 117: 613-622.

Rosin RA, Levine MD, Peskind E (2001). Transdermal nicotine for agitation in dementia. Am J Geriatr Psychiatry 9: 443-444.

Rubboli F, Court JA, Sala C, Morris C, Chini B, Perry E et al (1994). Distribution of nicotinic receptors in the human hippocampus and thalamus. Eur J Neurosci 6: 1596-1604.

Sala M, Caverzasi E, Lazzaretti M, Morandotti N, De Vidovich G, Marraffini E et al (2011). Dorsolateral prefrontal cortex and hippocampus sustain impulsivity and aggressiveness in borderline personality disorder. J Affect Disord 131: 417-421.

Schindelin J, Arganda-Carreras I, Frise E, Kaynig V, Longair M, Pietzsch T et al (2012). Fiji: an open-source platform for biological-image analysis. Nat Methods 9: 676-682.

Schneider R, Hoffmann HJ, Schicknick H, Moutier R (1992). Genetic analysis of isolation-induced aggression. I. Comparison between closely related inbred mouse strains. Behav Neural Biol 57: 198-204.

Sharp AJ, Mefford HC, Li K, Baker C, Skinner C, Stevenson RE et al (2008). A recurrent 15q13.3 microdeletion syndrome associated with mental retardation and seizures. Nat Genet 40: 322-328.

Shinawi M, Schaaf CP, Bhatt SS, Xia Z, Patel A, Cheung SW et al (2009). A small recurrent deletion within $15 \mathrm{q} 13.3$ is associated with a range of neurodevelopmental phenotypes. Nat Genet 41: 1269-1271.

Siegel A, Flynn JP (1968). Differential effects of electrical stimulation and lesions of the hippocampus and adjacent regions upon attack behavior in cats. Brain Res 7: 252-267.

Snyder JS, Radik R, Wojtowicz JM, Cameron HA (2009). Anatomical gradients of adult neurogenesis and activity: young neurons in the ventral dentate gyrus are activated by water maze training. Hippocampus 19: 360-370.

Son JH, Winzer-Serhan UH (2008). Expression of neuronal nicotinic acetylcholine receptor subunit mRNAs in rat hippocampal GABAergic interneurons. J Comp Neurol 511: 286-299.

Spielmann M, Reichelt G, Hertzberg C, Trimborn M, Mundlos S, Horn $\mathrm{D}$ et al (2011). Homozygous deletion of chromosome 15q13.3 including CHRNA7 causes severe mental retardation, seizures, muscular hypotonia, and the loss of KLF13 and TRPM1 potentially cause macrocytosis and congenital retinal dysfunction in siblings. Eur J Med Genet 54: e441-e445.

Tregellas JR, Olincy A, Johnson L, Tanabe J, Shatti S, Martin LF et al (2010). Functional magnetic resonance imaging of effects of a nicotinic agonist in schizophrenia. Neuropsychopharmacology 35: 938-942.

Tregellas JR, Tanabe JL, Miller DE, Ross RG, Olincy A, Freedman R (2004). Neurobiology of smooth pursuit eye movement deficits in schizophrenia: an fMRI study. Am J Psychiatry 161: 315-321.

Unger EK, Burke KJ Jr, Yang CF, Bender KJ, Fuller PM, Shah NM (2015). Medial amygdalar aromatase neurons regulate aggression in both sexes. Cell Rep 10: 453-462.

van der Kooij MA, Fantin M, Kraev I, Korshunova I, Grosse J, Zanoletti $\mathrm{O}$ et al (2014). Impaired hippocampal neuroligin-2 function by chronic stress or synthetic peptide treatment is linked to social deficits and increased aggression. Neuropsychopharmacology 39: 1148-1158.

Van Schalkwyk GI, Lewis AS, Qayyum Z, Koslosky K, Picciotto MR, Volkmar FR (2015). Reduction of aggressive episodes after repeated transdermal nicotine administration in a hospitalized adolescent with autism spectrum disorder. J Autism Dev Disord 45: 3061-3066.

Vermeiren Y, Van Dam D, Aerts T, Engelborghs S, De Deyn PP (2014). Monoaminergic neurotransmitter alterations in postmortem brain regions of depressed and aggressive patients with Alzheimer's disease. Neurobiol Aging 35: 2691-2700.

Yin J, Chen W, Yang H, Xue M, Schaaf CP (2017). Chrna7 deficient mice manifest no consistent neuropsychiatric and behavioral phenotypes. Sci Rep 7: 39941.

Zimmerman DW, Zumbo BD (1993). Relative power of the Wilcoxon test, the Friedman test, and repeated-measures ANOVA on ranks. J Exp Educ 62: 75-86.

Supplementary Information accompanies the paper on the Neuropsychopharmacology website (http://www.nature.com/npp) 